\title{
Routine immunization community surveys as a tool for guiding program implementation in Kaduna state, Nigeria 2015-2016
}

Terna I. Nomhwange ${ }^{1 *}$, Faisal Shuaib², Fiona Braka', Sambo Godwin ${ }^{3}$, Usman Kariko ${ }^{4}$, Umeh Gregory ${ }^{1}$, Sisay G. Tegegne', Bassey Okposen ${ }^{2}$ and Chima Onoka²

\begin{abstract}
Background: Routine childhood immunization remains an important strategy for achieving polio eradication and maintaining a polio-free world. To address gaps in reported administrative coverage data, community surveys were conducted to verify coverage, and guide strategic interventions for improved coverage.

Methods: We reviewed the conduct of community surveys by World Health Organization (WHO) field volunteers deployed as part of the surge capacity to Kaduna state and the use of survey results between July 2015 and June 2016. Monthly and quarterly collation and use of these data to guide the deployment of various interventions aimed at strengthening routine immunization in the state.

Results: Over 97,000 children aged 0-11 months were surveyed by 138 field volunteers across 237 of the 255 wards in Kaduna state. Fully or appropriately immunized children increased from 67\% in the fourth quarter of 2015 to $76 \%$ by the end of the second quarter of 2016 . Within the period reviewed, the number of local government areas with $<80 \%$ coverage reduced from eight to zero.
\end{abstract}

Conclusions: The routine conduct of community surveys by volunteers to inform interventions has shown an improvement in the vaccination status of children 0-11 months in Kaduna state and remains a useful tool in addressing administrative data quality issues.

Keywords: Routine immunization, Community survey, Immunization status, Kaduna

\section{Background}

Childhood Immunization is a critical cost effective strategy used globally to reduce infant and under 5-year-old mortality rates [1]. In a bid to achieve Sustainable Development Goal (SDG) Goal 3 and related targets, countries have made commitments to addressing access issues with the clamor for Universal Health Coverage [2-4]. The decade of vaccines vision, as described in strategic documents like the Global Vaccine Action Plan (GVAP), lists objectives and recommendations towards improving health by 2020 and beyond, through providing the full benefits of immunization to all [5]. The economic benefits of vaccines are even more critical in Low and Middle-Income Countries (LIMC) with increasing competing priorities with the need to introduce new vaccines $[6,7]$.

Nigeria marked 2 years without a case of paralytic Wild Polio Virus (WPV) until the recent isolation of three cases in Borno state in 2016 as it prepared for a post-polio immunization system and its recent removal

\footnotetext{
* Correspondence: nomhwanget@who.int

${ }^{1}$ World Health Organization Country Office, Abuja, Nigeria

Full list of author information is available at the end of the article
}

(c) The Author(s). 2018 Open Access This article is distributed under the terms of the Creative Commons Attribution 4.0 International License (http://creativecommons.org/licenses/by/4.0/), which permits unrestricted use, distribution, and 
and consequent reversal from the list of polio-endemic countries $[8,9]$. To achieve this, a robust system that will deliver routine vaccines through various routine immunization strategies remains critical [10]. The Nigeria expert review committee (ERC) on polio and routine immunization, at its 32nd meeting, held on the 19th and 20th of June 2016 in Abuja, highlighted the need to invest in strengthening routine immunization through a comprehensive primary health care strategy [11]. Various such interventions are ongoing in the country with a focus on 107 identified high-risk Local Government Areas (LGAs) with significant improvement in coverage [12]. Some of these efforts are hampered by challenges in measuring impact using administrative data [13]. Multiple intermittent immunization surveys conducted across the country show differences between administrative data and survey outcomes $[14,15]$.

Kaduna state, located in northwest Nigeria is one of the 11 high-risk states for polio transmission and has recently enacted a primary health care under one roof (PHCUOR) law and established the state primary health care agency with a primary mandate to improve primary health care services.

A total of 1094 health facilities provide routine immunization (RI) services to a targeted population of 326,118 infants; delivering all vaccines based on the national immunization schedule. The Nigeria Demographic Health Survey (NDHS) 2013 reported routine immunization coverage of $43.7 \%$ for the third dose of Diphtheria-Pertussis-Tetanus (DPT) vaccine (now replaced by the pentavalent vaccine) and $44.4 \%$ for Oral Polio Vaccine (OPV3) in Kaduna state [16]. Data quality and gaps in the information management has been a challenge affecting the routinely reported administrative data [17].

Guidelines have been reviewed with strategies proposed to address the impact of data quality on program implementation with guidance documented in the country multiyear plan (cMYP) 2016-2020 [18]. Immunization surveys to validate administrative data have been advocated for, and various surveys conducted showed wide variation between local government areas (LGA) and state reported administrative data [10]. The use of community surveys to address gaps and strengthen administrative data management have been proposed as well as considerations of alternatives for measuring routine immunization performance [19].

Kaduna state has over the years experienced various degrees of outbreaks of measles and cerebrospinal meningitis (CSM) despite very high administrative coverage data of routine antigens. In line with the surge in health worker capacity of WHO in Nigeria, personnel and field volunteers have been deployed to various communities.These personnel supervise RI services and conduct surveys of children aged 0-11 monthly using standard program tools and checklists and document vaccination status at sub-district levels to be used to guide and support program interventions.

This study reviews the surveys conducted across Kaduna state involving more than 90,000 children between 2015 and 2016 and its use to guide the implementation of various RI interventions at LGA and state levels. It also reports on survey documentation as a best practice regarding polio legacy and its use in transition planning [20].

\section{Methods}

\section{Outline of the study design}

We conducted a retrospective study to review the trends of community surveys conducted across various communities in Kaduna state across four quarters between July 2015 and June 2016 of children < 1 year of age who were fully or appropriately immunized for age in Kaduna state.

Quantitative data showing various vaccination status variables including the number of settlements and wards was analyzed, and we also reviewed the routine immunization administrative coverage data reported by LGA and state within the same period.

\section{Subjects}

A total of 138 field volunteers had been deployed across 255 wards of the 23 LGAs of Kaduna state based on the World Health Organization (WHO) Nigeria surge capacity to improve program implementation. These levels of staff were mandated, as documented in their terms of reference (TOR), to conduct a minimum of one community survey per month in any settlement in the catchment area of the health facilities in the ward of assignment using a community survey checklist. The adherence to this task was ensured by the WHO accountability framework and quarterly administrative action from the Office of the WHO Representative (WR) in Nigeria with all assigned responsibilities accessed accordingly [21].

A total of 9557 surveys involving 96,597 children aged 0-11 months were conducted across the 23 LGAs between July 2015 and June 2016.The sample size for each survey was 10 children per selected settlement was based on the standard protocol of the WHO Nigeria field volunteer's checklist and field guide for staff.

All survey data with complete information for 10 children sampled with complete information on all variables as shown on the field volunteer's checklist. Children in households where mothers were not at home at the time of visits, consent not given by caregivers or selected households with children aged greater than 12 months or incomplete documentation on the checklist were discarded. The study utilized 
Table 1 Special Interventions deployed in Kaduna state to address areas with low proportions of fully or appropriately immunized children

\begin{tabular}{|c|c|c|c|}
\hline Thematic Area & Intervention & Target & Expected Outcome \\
\hline Service Delivery & Expanded Outreach Services & $\begin{array}{l}\text { Communities far from Health } \\
\text { Center ( }>5 \mathrm{Kms})\end{array}$ & Increase Immunization coverage \\
\hline Service Delivery & Transit Point Vaccination & $\begin{array}{l}\text { Mobile Population and child } \\
\text { at risk of being missed }\end{array}$ & Increase vaccination coverage \\
\hline Service Delivery & Health Camps & Under 5 children and Mothers & $\begin{array}{l}\text { Treatment of minor ailments, } \\
\text { deworming, health promotion }\end{array}$ \\
\hline Service Delivery & $\begin{array}{l}\text { Maternal, Neonatal and Child } \\
\text { Health (MNCH) week }\end{array}$ & $\begin{array}{l}\text { Pregnant mothers and children } \\
\text { less than } 5 \text { years }\end{array}$ & $\begin{array}{l}\text { Improved Maternal and Child/ } \\
\text { Neonatal Care }\end{array}$ \\
\hline Service Delivery & Mobile Health Teams & $\begin{array}{l}\text { Hard to reach Population (Distance, } \\
\text { geography, financial) }\end{array}$ & $\begin{array}{l}\text { Increase health outcomes for at-risk } \\
\text { populations }\end{array}$ \\
\hline Communication \& Social Mobilization & Newborn referrals & Mothers of Babies born at home & Increased neonatal health \\
\hline Communication \& Social Mobilization & Defaulter Tracking & $\begin{array}{l}\text { Caregivers or mothers of children } \\
\text { who have missed an immunization } \\
\text { appointment }\end{array}$ & $\begin{array}{l}\text { Reduction in Vaccination drop-out } \\
\text { rates }\end{array}$ \\
\hline Vaccine stock management & Vaccine dashboard & Health facilities & $\begin{array}{l}\text { Reduction of vaccines stock out } \\
\text { reports }\end{array}$ \\
\hline Data managements & $\begin{array}{l}\text { Monitoring/Distribution of } \\
\text { vaccine data tools/Child Cards }\end{array}$ & Health Facilities & $\begin{array}{l}\text { Increased data quality and } \\
\text { Documentation of services provided }\end{array}$ \\
\hline Vaccine Delivery & Vaccine push & Health Facility & Availability of vaccines at all sessions \\
\hline
\end{tabular}

the weekly submissions of field volunteer survey checklists which was transferred to a simple Microsoft Excel $^{\circledR}$ template for collation with the capture of details showing the date of survey, settlement name, ward and classification of children according to vaccination status. This was done monthly at the LGA level and quarterly in the state.

\section{Measurements}

Data was measured in proportions of vaccination status of all children surveyed and also displayed as simple quarterly trends to show the pattern of various vaccination statuses.

The average number of settlements and wards per quarter were documented. A review of routine immunization administrative coverage data for first and third doses of Pentavalent and oral polio vaccine (OPV) was also shown at LGA and state levels.

Table 2 Summary of Children showing number of settlements and wards surveyed by field staff in Kaduna state July 2015-June 2016

\begin{tabular}{llll}
\hline & Settlements & Wards & No of Children Surveyed \\
\hline Q3 2015 & 2407 & 241 & 23,921 \\
Q4 2015 & 2111 & 222 & 21,216 \\
Q1 2016 & 2517 & 246 & 26,221 \\
Q2 2016 & 2563 & 240 & 25,649 \\
Average & 2400 & 237 & \\
\hline
\end{tabular}

\section{Procedure}

All designated WHO staff at quarterly program review meeting were re-sensitized and reoriented on the process for community surveys using the field volunteer's checklist. The identified template for collation and capture of surveys was also discussed and shared with all LGA facilitators (first line supervisors of the field supervisors) for monthly collation and timelines for quarterly submission to the state level monitoring and evaluation (M\&E) Officer. The template included various validation checks to reduce entry errors as well as automatically generated graphs to show simple analysis of vaccination status by ward and LGA.

Surveys were conducted by the staff after community entries and permission by village gatekeepers, mainly the village head and consent by caregiver sort and given, in selected households to participate in the survey. Vaccination status was documented using vaccination cards with an assessment of vaccination status for the current

Table 3 Distribution of completeness of survey of children aged 0-11 months by Quarter Kaduna July 2015-June 2016

\begin{tabular}{lll}
\hline & $\begin{array}{l}\text { Expected Children to } \\
\text { be survey per Quarter }\end{array}$ & $\begin{array}{l}\text { Reported Children } \\
\text { surveyed per quarter }\end{array}$ \\
\hline Q3 2015 & 4140 & 23,921 \\
Q4 2015 & 4140 & 21,216 \\
Q1 2016 & 4140 & 26,221 \\
Q2 2016 & 4140 & 25,649 \\
Total & 16,560 & 97,007 \\
\hline
\end{tabular}




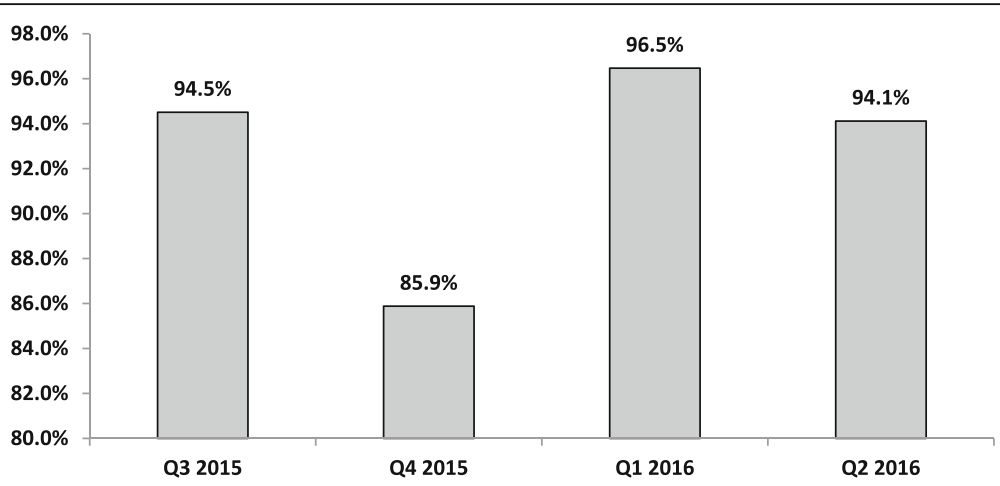

Fig. 1 Proportion of wards where surveys were conducted in Kaduna July 2015-June 2016

age of child based on the current EPI schedule for Nigeria.

Sampling technique for surveys included skipping 1 or 2 households in settlements with less than 10 or greater than 20 Households respectively. A selected household without an eligible child was skipped and the next household with a child sampled.

Collated data were reviewed and proportions of various vaccination status category including "fully or appropriately immunized," "partially immunized" and "not

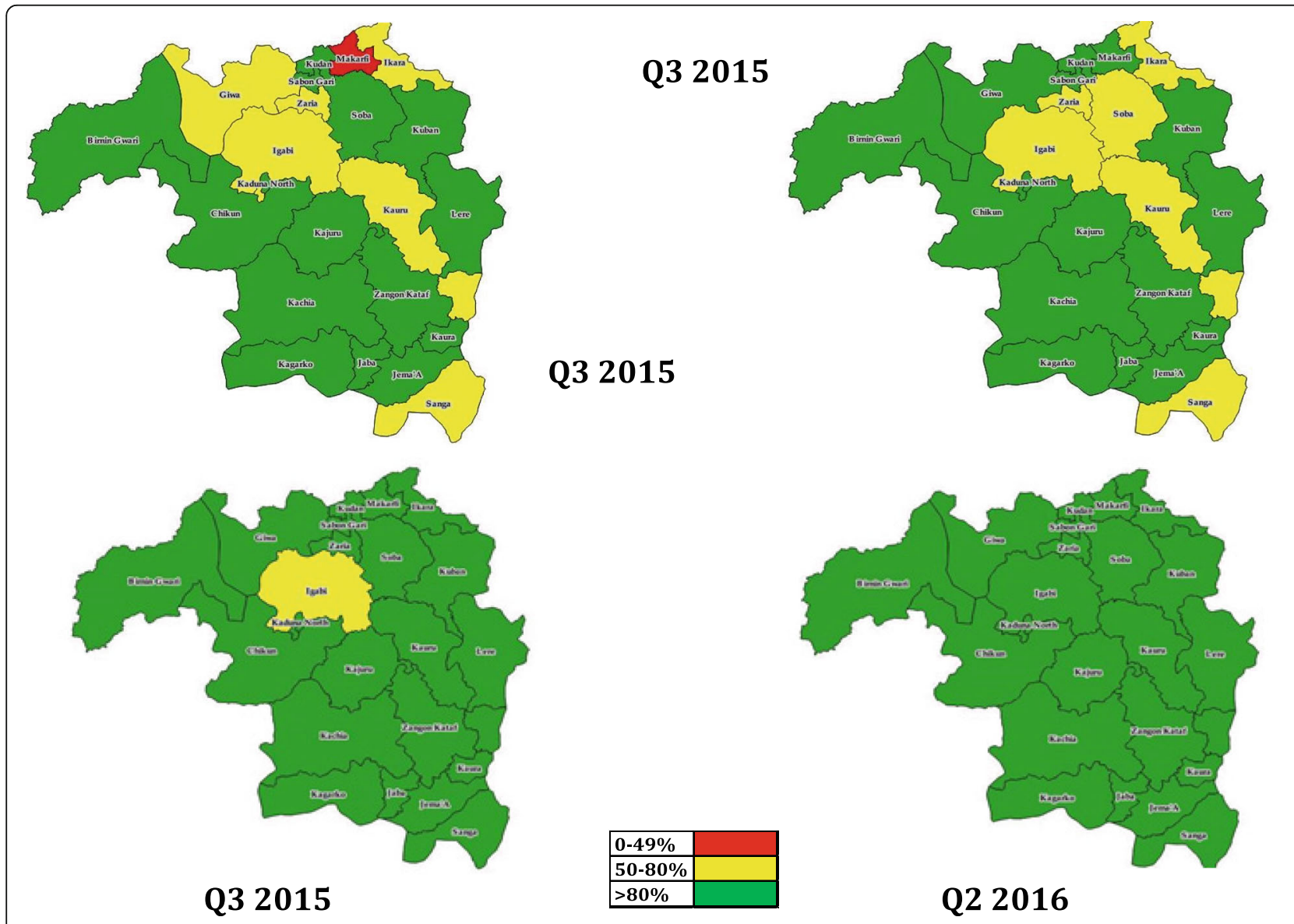

Fig. 2 Categorization of LGAs by the third dose of Pentavalent Vaccine Coverage of LGAs in Kaduna state Jan 2015 - June 2016 


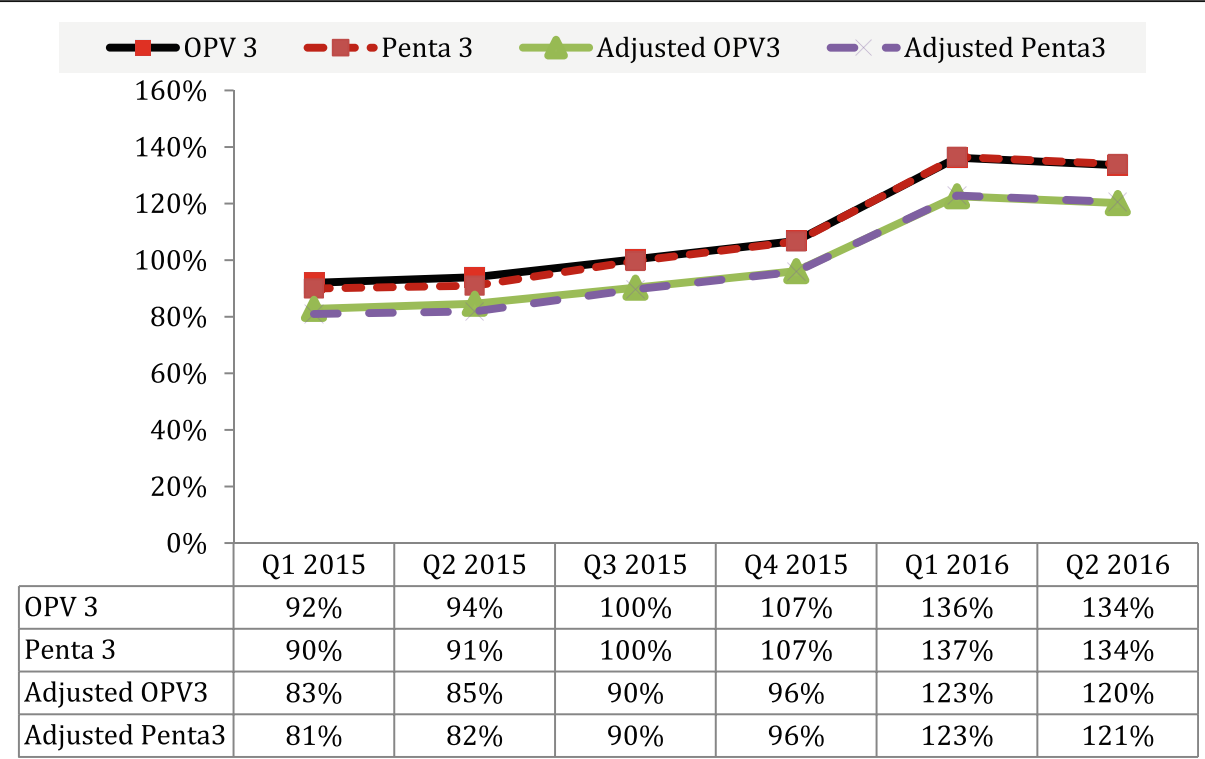

Fig. 3 Trend of state Administrative Quarterly RI coverage of Penta3 and OPV3 in Kaduna January 2015-June 2016

immunized" and shared at the state emergency operations center $(\mathrm{sEoC})$ and comparison with administrative data. LGA and ward survey reports were reviewed and interventions best suited deployed. These interventions deployed based on best fit are outlined in Table 1 .

At the LGA level, these survey reports were shared with the local immunization officer, director of health and displayed at the government office by ward conspicuously. This data set was also discussed at the monthly review meetings with routine immunization providers for all health facilities in the LGA with clear directives on action points to address issues in a settlement with low levels of appropriately immunized children including supportive supervision.

\section{Results}

A total of 97,007 children aged $0-11$ months were surveyed between July 2015 and June 2016 by 138 field level staff in Kaduna state (Table 2). These surveys were conducted in a number of wards ranging from 222 to 246 across the four quarters under review involving an average of 24,252 children per quarter.
In total, 97,007children were surveyed as against the expected 16,560 as recommended between July 2015 and June 2016 (Table 3). The highest number of children were surveyed in quarter one of 2016 and the least in quarter 4 of 2015.This survey spread ranged from 241 wards in quarter 3 of 2015 to 240 in quarter 2 of 2016 (Fig. 1) across the 255 wards in Kaduna state with differences in wards surveyed across quarters. An average of 237 Wards and 2400 settlements were surveyed per quarter.

In 2015, eight LGAs reported Penta 3 coverage < 80\% in quarter 1 of 2015, and 6 LGAs in quarter 2 of 2015 reported Penta 3 coverage <80\% (Fig. 2). Only Igabi LGA in quarter 32015 had a coverage level of between 50 and $80 \%$ while all LGAs in quarter 22016 reported coverages of $>80 \%$.

The third dose of oral polio vaccine (OPV3) and Penta 3 was 90 and $92 \%$ respectively in quater 12015 , OPV3 94\% and Penta $391 \%$ in quater2 2015, 100\% in quater3 2015, and 107\% in quater4 2016 (Fig. 3). In 2016, the reported administrative coverage reported was 136 and $137 \%$ for OPV3 and Penta 3 respectively quarter 1 and $134 \%$ each in quarter 2 .

Table 4 Distribution showing vaccination status of children aged 0-11 Months from community surveys conducted by field staff in Kaduna state July 2015-June 2016

\begin{tabular}{lllll}
\hline & Fully/Appropriately Immunized (\%) & Partially Immunized (\%) & Not Immunized (\%) & Total \\
\hline Q3 2015 & $16,014(67 \%)$ & $5897(25 \%)$ & $2010(8 \%)$ & 23,921 \\
Q4 2015 & $14,279(67 \%)$ & $5291(25 \%)$ & $1646(8 \%)$ & 21,216 \\
Q1 2016 & $18,541(71 \%)$ & $5165(20 \%)$ & $2515(10 \%)$ & 26,221 \\
Q2 2016 & $19,401(76 \%)$ & $4712(18 \%)$ & $1536(6 \%)$ & 25,649 \\
Total & 68,235 & 21,065 & 7707 & 97,007 \\
\hline
\end{tabular}




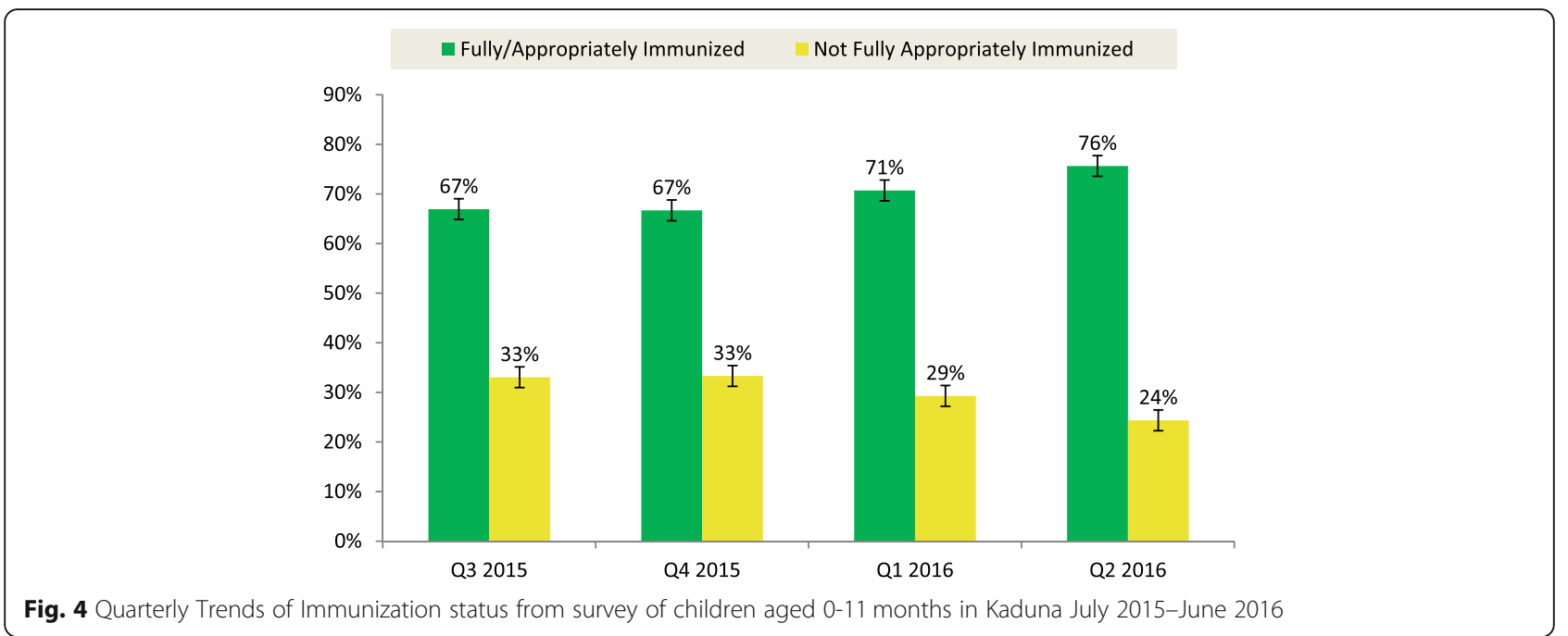

The state administrative coverage for the third dose of Penta and OPV coverage trend by quarter shows increases bore both vaccines between 2015 and 2016 . (Also adjusted based on data quality audit (DQA) conducted by the state in 2015 with an over-reporting factor of $10 \%$ ).

The summary of children surveyed and their vaccination status was documented across four quarters (Table 4). The proportion of children fully or appropriately immunized was $67 \%$ in quarter 3 of 2015 and $76 \%$ in quarter 2 2016. The proportion of children not appropriately immunized reduced from $33 \%$ in quarter 3 of 2015 to $24 \%$ by the end of quarter 2 in 2016 (Fig. 4). This trend is seen with a difference between Fully and not fully immunized children increasing from 34 to $52 \%$ (Table 5).

\section{Discussion}

In our reviews of the outputs of the surveys conducted in Kaduna state involving > 90,000 children between July 2015 and June 2016, we found an increasing trend of fully or appropriately immunized children from $67 \%$ in quarter 32015 to 76\% in quarter 2 2016.The use of these routine surveys results to guide various routine immunization intensification activities has also shown to have a positive impact on routine immunization coverage in Kaduna with an increase of Penta 3 coverage data

Table $\mathbf{5}$ Comparison of proportion of vaccination status by quarter July 2015-June 2016

\begin{tabular}{llll}
\hline & Fully Immunized & Not Fully Immunized & Variance (\%) \\
\hline Q3 2015 & $67 \%$ & $33 \%$ & $34 \%$ \\
Q4 2015 & $67 \%$ & $33 \%$ & $34 \%$ \\
Q1 2016 & $71 \%$ & $29 \%$ & $42 \%$ \\
Q2 2016 & $76 \%$ & $24 \%$ & $52 \%$ \\
\hline
\end{tabular}

from $90 \%$ before the use of these survey data to $134 \%$ by the end of June 2016.This result is similar to documented variance with survey data seen to be less than administrative values in South Sudan [22].

The impact was also seen at lower levels of an increase in the number of LGAs with Penta 3 coverage from 65 to $100 \%$. We have also shown a reduction in variance between OPV3 and Penta3 coverage, antigens scheduled at the same hospital visit, a simple method for data quality check. We have also shown increases in surveys conducted in quarter 1 and quarter2 of 2016 compared to those done in 2015. We attribute this to increasing awareness of the importance of the surveys and more interest by the Local authorities' staff to support the process.

Not all 255 wards in Kaduna state were surveyed within the study period. The survey scope was highest in Q1 2016 and lowest in Q4 2015.This variance in surveys in wards are linked to the decision by field staff to focus on settlements they consider as poor performing regarding routine immunization based on information from the Health facility supervisory visit. We, however, note that some data submissions with quality issues or surveys not done based on guidelines were discarded. Even though we also see variation in numbers of settlements, we have noted that some settlements were surveyed more than once within the period of the survey. These repeat surveys were only conducted in specifically highlighted settlements with clear risks such as disease outbreaks of VPDs or validation visits of interventions already deployed.

Even though a huge number of children were sampled in these surveys, our study was limited by the fact that not all the wards and settlements in the state were surveyed, and surveys were mainly conducted around communities close to a health facility. This limitation is 
based on the current staff deployment of 138 field officers in the state. This limitation can be addressed by the push for the involvement of by LGA and state Health personnel which could then ensure sure complete state coverage. The limitation of surveys around health facilities is based on transportation cost as the personnel are also not provided with any means of transportation or entitled to transportation reimbursements. With increasing government buy-in and participation, health department vehicles may subsequently be available for the conduct of settlement surveys far from the health facilities but within the reaching every ward (REW) catchment area of the health facility.

This study has shown that routinely administered community of surveys in Kaduna has been used effectively to guide the various routine immunizations intervention activities in the state with a resultant increase in state and LGA level administrative data and with high-level coordination support shown improvement inappropriately immunized children.

We recommend the continuous routine conduct of household surveys by local government, other partner and all field staff at regular intervals and use of vaccination status of children under 1 year to routine immunization activities across Nigeria and other developing countries with administrative data management challenges. These surveys can also be useful in strengthening immunization systems and PHC delivery. Tao W et al. have suggested that reported routine immunization coverage may be lower than reported [23]. Sustaining these interventions that address gaps in data quality remain critical to maintaining high coverage, thus protect children from preventable diseases and death.

\section{Conclusion}

Community surveys are a very effective tool to guide implementation of routine immunization services at community levels with a noticeable increase in proportion of fully immunized children. The use of simple tools to track vaccination status of children and provide regular feedback to program authority at local levels remain critical in the push to reach all eligible children with vaccines and improve coverage.

\footnotetext{
Abbreviations

CMYP: Country multiyear plan; CSM: Cerebrospinal meningitis;

DPT: Diphtheria Pertussis Tetanus containing vaccine; DQA: Data quality audit; EPI: Expanded programme on immunization; ERC: Expert review committee; GVAP: Global vaccination action plan; LGA: Local government area; LMIC: Low and middle income countries; M\&E: Monitoring and evaluation; NDHS: Nigeria demographic health survey; OPV: Oral polio vaccine; PHCUOR: Primary health care under one roof; REW: Reaching every ward; RI: Routine immunization; SDG: Sustainable development goal; SEOC: State emergency operations centre; TOR: Terms of reference; VPD: Vaccine preventable diseases; WHO: World health organization; WPV: Wild polio virus
}

\section{Acknowledgements}

The authors will like to thank all the field volunteers in Kaduna state who on a daily basis ensure the delivery of life saving vaccines at the last mile of the service delivery chain. We also appreciate the efforts of Mr. Hilary Adole and Mr. Danjuma Udoji and all the LGA facilitators supporting the WHO field office in Kaduna state.

Funding

Publication of this article was sponsored by the WHO Nigeria country office best practices documentation funds).

\section{Availability of data and materials}

Data available as part of the programmatic data collated at state levels and could be made available from the principal author upon request.

\section{About this supplement}

This article has been published as part of BMC Public Health Volume 18 Supplement 4, 2018: Experiences and lessons learned in polio eradication in Nigeria. The full contents of the supplement are available online at https:// bmcpublichealth.biomedcentral.com/articles/supplements/volume-18supplement-4.

\section{Authors' contributions}

TN, FS and FB conceptualized this work and prepared the zero draft. SG, UK and UG coordinated and supported the data preparation and analysis. ST, BO and $\mathrm{CO}$ contributed to the initial drafts. All authors have contributed in the final reviews of the final draft and have read and approved the final draft.

\section{Ethics approval and consent to participate}

Not applicable. Programmatic data (secondary data) used for this study. Data used for this work was made available by the Kaduna state EoC and WHO state Offices.

\section{Consent for publication}

Our manuscript contained no personal individual information and so consent was obtained for this publication.

\section{Competing interests}

The authors declare that they have no competing interests.

\section{Publisher's Note}

Springer Nature remains neutral with regard to jurisdictional claims in published maps and institutional affiliations.

\section{Author details}

${ }^{1}$ World Health Organization Country Office, Abuja, Nigeria. ${ }^{2}$ National Primary Health Care Agency, Abuja, Nigeria. ${ }^{3}$ World Health Organization, Kaduna Field Office, Kaduna, Nigeria. ${ }^{4}$ Kaduna State Primary Healthcare Development Agency, Kaduna, Nigeria.

Published: 13 December 2018

\section{References}

1. Morbidity MM, Weekly M, May R. Vaccine preventable deaths and the global immunization vision and strategy, 2006-2015. MMWR Morb Mortal Wkly Rep. 2006;55(18):511-5.

2. SDGs. Sustainable Development Knowledge Platform. Available from: https://sustainabledevelopment.un.org/sdgs Date accessed 24 Nov 2017.

3. Okpani Al, Abimbola S. Nigeria 2015 Millennium Development Goals: End Point Report. 2015.

4. Okpani A, Abimbola S. Operationalizing universal health coverage in Nigeria through social health insurance. Niger Med J. 2015;56(5):305 Available from: http://www.nigeriamedj.com/text.asp?2015/56/5/305/170382 Date accessed 24 Nov 2017. Cited 26 Aug 2016.

5. Decade of Vaccine Collaboration. Global vaccine action plan. Decade of vaccine collaboration. Vaccine. 2013;31(Suppl 2):B5-31 Available from: http://www.sciencedirect.com/science/article/pii/S0264410X13001680 http:// linkinghub.elsevier.com/retrieve/pii/S0264410X13001680 http://www.ncbi. nlm.nih.gov/pubmed/23734366. 
6. Shen AK, Fields R, McQuestion M. The future of routine immunization in the developing world: challenges and opportunities. Glob Heal Sci Pract. 2014; 2(4):381-94

7. Hajjeh R. Accelerating introduction of new vaccines: barriers to introduction and lessons learned from the recent Haemophilus influenzae type $B$ vaccine experience. Philos Trans R Soc Lond Ser B Biol Sci. 2011;366(1579):2827-32.

8. Patel M, Zipursky S, Orenstein W, Garon J, Zaffran M. Polio endgame: the global introduction of inactivated polio vaccine. Expert Rev Vaccines. 2015; 14(5):749-62 Available from: http://www.tandfonline.com/doi/full/10.1586/ 14760584.2015.1001750.

9. WHO. Government of Nigeria reports 2 wild polio cases, first since July 2014: WHO; 2016. http://www.who.int/news-room/detail/11-08-2016government-of-nigeria-reports-2-wild-polio-cases-first-since-july-2014.

10. Ali D, Banda R, Mohammed A, Adagadzu J, Murele B, Seruyange R, et al. Strengthening routine immunization in areas of northern Nigeria at high risk for polio transmission during. 2012;

11. ERC. 32st meeting of the expert review committee on Polio Eradication \& Routine Immunization in Nigeria 20-21 June 2016; 2016. p. 1-33. Available from: https://afro.who.int/news/experts-recommend-strategic-shift-nigeriaspolio-eradication-programmme. Cited 26 Aug 2016

12. Machingaidze $S$, Rehfuess $E$, von Kries R, Hussey GD, Wiysonge CS Understanding interventions for improving routine immunization coverage in children in low- and middle-income countries: a systematic review protocol. Syst Rev. 2013;2:106 Available from: http://www.pubmedcentral. nih.gov/articlerender.fcgi?artid=3843560\&tool=pmcentrez\&rendertype $=$ abstract.

13. Dunkle SE, Wallace AS, MacNeil A, Mustafa M, Gasasira A, Ali D, et al. Limitations of using administratively reported immunization data for monitoring routine immunization system performance in Nigeria. J Infect Dis. 2014;210:S523-30 Oxford University Press.

14. Ronveaux O, Rickert D, Hadler S, Groom H, Lloyd J, Bchir A, et al. The immunization data quality audit: verifying the quality and consistency of immunization monitoring systems. Bull World Health Organ. 2005:83(7):503-10.

15. Mavimbe JC, Braa J, Bjune G. Assessing immunization data quality from routine reports in Mozambique. BMC Public Health. 2005:5:108.

16. NPC Nigeria \& ORC Macro. Nigeria demographic and health survey 2013. National Population Commission Federal Republic of Nigeria. 2014.

17. Steinglass R. Routine immunization: an essential but wobbly platform. Glob Heal Sci Pract. 2013;1(3):295-301 Available from: http://www.ghspjournal. org/content/1/3/295.full.

18. Primary N, Care H, Agency D. Federal Ministry of Health, Nigeria comprehensive EPI multi-year plan 2016-2020 National Primary Health Care Development Agency. 2016;

19. Vashishtha VM. Status of immunization and need for intensification of routine immunization in India. Indian Pediatr. 2012;49:357-61.

20. Cochi SL, Freeman A, Guirguis S, Jafari H, Aylward B. Global polio eradication initiative: lessons learned and legacy. J Infect Dis. 2014;210: S540-6.

21. Tegegne SG, Mkanda P, Yehualashet YG, Erbeto TB, Touray K, Nsubuga P, et al. Implementation of a Systematic Accountability Framework in 2014 to Improve the Performance of the Nigerian Polio Program. J Infect Dis. 2016; 213(suppl_3):S96-100.

22. Mbabazi W, Lako AK, Ngemera D, Laku R, Yehia M, Nshakira N. Maiden immunization coverage survey in the republic of South Sudan: a crosssectional study providing baselines for future performance measurement. Pan Afr Med J. 2013;16:110

23. Tao W, Petzold M, Forsberg BC. Routine vaccination coverage in low-and middle-income countries: further arguments for accelerating support to child vaccination services. Glob Health Action. 2013;6(1):20343.

Ready to submit your research? Choose BMC and benefit from:

- fast, convenient online submission

- thorough peer review by experienced researchers in your field

- rapid publication on acceptance

- support for research data, including large and complex data types

- gold Open Access which fosters wider collaboration and increased citations

- maximum visibility for your research: over $100 \mathrm{M}$ website views per year

At BMC, research is always in progress.

Learn more biomedcentral.com/submissions 